\title{
The Pressure and Efficiency Characteristic of Hydraulic Gerotor Motor with the Floating Outer Ring
}

\author{
Ervin STRMČNIK, Franc MAJDIČ
}

\begin{abstract}
A gerotor with the floating outer ring is a low speed high torque hydraulic motor. It is a special type of hydraulic motor, which is very rarely described in literature. In this study, the pressure and efficiency characteristics of hydraulic gerotor motor were investigated. The main purpose of this scientific paper was to analyse the influence of the size of the holes in the valve plate on total efficiency of the gerotor. The total efficiency is the most important and prominent information about energy conversion of hydraulic components such as hydraulic motors and pumps. The operation of gerotor is briefly described as well as some equations for the determination of efficiency. In a section of the methodology, a measurement procedure is presented in detail. A test rig with hydraulic components and sensors was introduced. The analysis was carried out to respect the international standards. With the help of measurement, we determined the pressure distribution in some specific chambers in the hydraulic gerotor motor. The results show that there is correlation between the size of holes in the valve plate and the total efficiency of the gerotor. Furthermore, a very high total efficiency was obtained with the hole size of $\Phi 6,3 \mathrm{~mm}$. In that case, the total efficiency was on average $5 \%$ higher in comparison to the initial hole size of $\phi 5,5 \mathrm{~mm}$.
\end{abstract}

Keywords: hydraulic-mechanical efficiency; orbital hydraulic motor; pressure determination; total efficiency; volumetric efficiency

\section{INTRODUCTION}

Even though hydraulics is quite a mature field in mechanical engineering, there are many exploratory challenges. The rapid development of the hydraulic components in the last few years has contributed many novelties, inovations and improvements in hydraulics. One of the groups of hydraulic components is hydraulic motor group. Hydraulic motors convert hydraulic energy into mechanical energy. The most crucial measure of performance of the hydraulic motor is the total efficiency. In this paper, the results of the measurement of slow rotation orbital hydraulic motor are presented. There are many factors which influence the hydraulic motor performance. They are related to hydraulic, tribological, material and other challenges. The performance of the hydraulic motor depends on the construction parameters as well. A gear pair has the largest influence on performance, whereas other parameters are also very important. We investigated the pressure conditions and the influence of the size of the holes in the valve plate. The holes are important for inlet and outlet flow of the fluid. Fluid takes care of the relative movement of the gear pair and lubrication of the main parts of the hydraulic motor. Within research we found out that the diameter of the holes in the valve plate influences hydraulic motor performance significantly. With the right choice of the hole diameter, we can raise the total efficiency on average around $5 \%$.

The paper is structured as follows. In the introduction is described the objective and the purpose of the research. Section 2 presents the theoretical framework of the conducted research. Hydraulic gerotor motor was described as well as procedure for the determination of the volumetric, mechanical-hydraulic and total efficiency. Furthermore, the calculation of the gerotor's derived displacement volume is proposed according to the international standard ISO 8426. Methodology is described in Section 3. A test rig of the experiment is shown in Section 4. The Results are presented in Section 5 and conclusions are summarized in Section 6. In the last two sections, there is a list of references and a nomenclature explanation.

\subsection{Literature Review}

In literature, there exist very few scientific papers which deal with hydraulic gerotor motor with the floating outer ring. Usually the classical orbital hydraulic motor with inner rotor and gerotor's housing is analysed. There are many factors which influence the performance of the gerotor. The viscosity, viscosity index, high-shear viscosity, piezoviscosity and shear stability of prototype fluids have been characterized in the research of fluid properties influence on the total efficiency of low-speed high torque hydraulic motors [1]. A very important influence on the total efficiency of hydraulic motor or pump is exerted by the geometry of the gear pair [2, 3, 4]. In the past few decades, many designs have been disclosed in relative patents, but many of them were not feasible for actual motor production. A kind of deep analysis of multiple performance attributes and structural design of the gerotor motor has been extensively investigated through multi-objective optimization design of the gerotor motor [5]. Pressure distribution within gerotor and some other physical quantities were analysed through a CFD model for orbital gerotor motor [6]. A CFD analysis helps us to understand the physics of gerotor's operation and enables a rapid development of new hydraulic motors [7]. The total efficiency is very much related to losses. Experimental and torque losses in gerotor were investigated in case of hydrostatic machines which represent complex fluid dynamic systems due to intricate and partially unknown dynamics [8]. Some losses are related to tribological behaviour. The most important are friction [9] and wear [10, 11].

Regarding rotational speed, there are two types of hydraulic motors. A low speed hydraulic motor does not exceed the rotational speed of $250 \mathrm{~min}^{-1}$. On the other hand, a high speed hydraulic motor reaches rotational speed higher than $250 \mathrm{~min}^{-1}$. A difference between the above mentioned groups is shown in Fig. 1 [12]. The low speed hydraulic motors achieve a higher total efficiency when they rotate relatively slowly (Fig. 1, line 1). The total efficiency of the high speed hydraulic motor increases in case of the rising rotational speed (Fig. 1, line 2). 


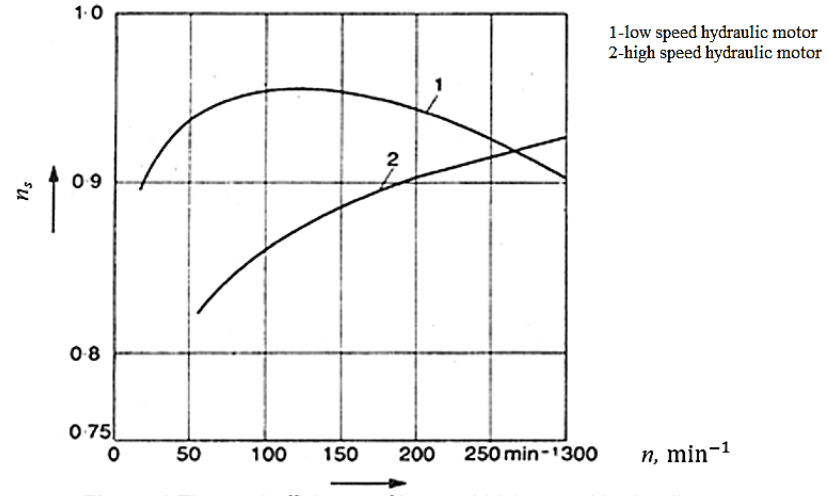

Figure 1 The total efficiency of low and high speed hydraulic motor

Table 1 Precendence and limitations of the hydraulic gerotor motor

\begin{tabular}{|l|l|}
\hline \multicolumn{1}{|c|}{ Precedence } & \multicolumn{1}{c|}{ Limitations } \\
\hline - relatively simple construction & - friction \\
compared to other types of & - wear \\
hydraulic motors & - low sealing ability of lobes \\
- high torque & between the inner rotor and \\
- low speed & outer ring \\
- self-braking ability & - low total efficiency \\
- relatively small and light & \\
- relatively cheap & \\
\hline
\end{tabular}

Nowadays, there are many different types of hydraulic motors. Gear, vane, axial piston and radial piston hydraulic motor. Geroller and gerotor are two special types of gear hydraulic motors. Our scientific paper deals with the gerotor, which has two special characteristics. It is a low speed hydraulic motor with high torque capability. In literature, it is often abbreviated to LSHT (Low Speed High Torque). Other precedences and limitations are listed in Tab. 1.

\section{HYDRAULIC GEROTOR MOTOR WITH THE FLOATING OUTER RING}

In this section we would like to present the hydraulic gerotor motor with the floating outer ring, its design, and principle of operation. At the end of the section we will introduce the procedure of displacement volume and efficiency determination for such a type of hydraulic motor.

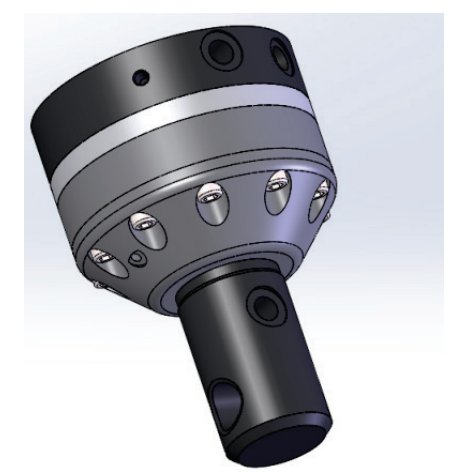

Figure 2 The hydraulic gerotor motor design $(\varnothing 174 \times 250 \mathrm{~mm})$

\subsection{Design and Principle of Operation of the Gerotor}

The hydraulic gerotor motor consists of thirty different parts. The maximum diameter is $\varnothing 174 \mathrm{~mm}$, whereas the maximum dimension represents the length of the gerotor - it is $250 \mathrm{~mm}$ (Fig. 2). Gerotor has a mass of around $20 \mathrm{~kg}$. Its working pressure is up to $35 \mathrm{MPa}$.

The most important parts of the hydraulic motor regarding principle of operation are: 1 - the inner rotor, 2 the outer ring, 3 - the gerotor housing and 4 - the valve plate (Fig. 3).

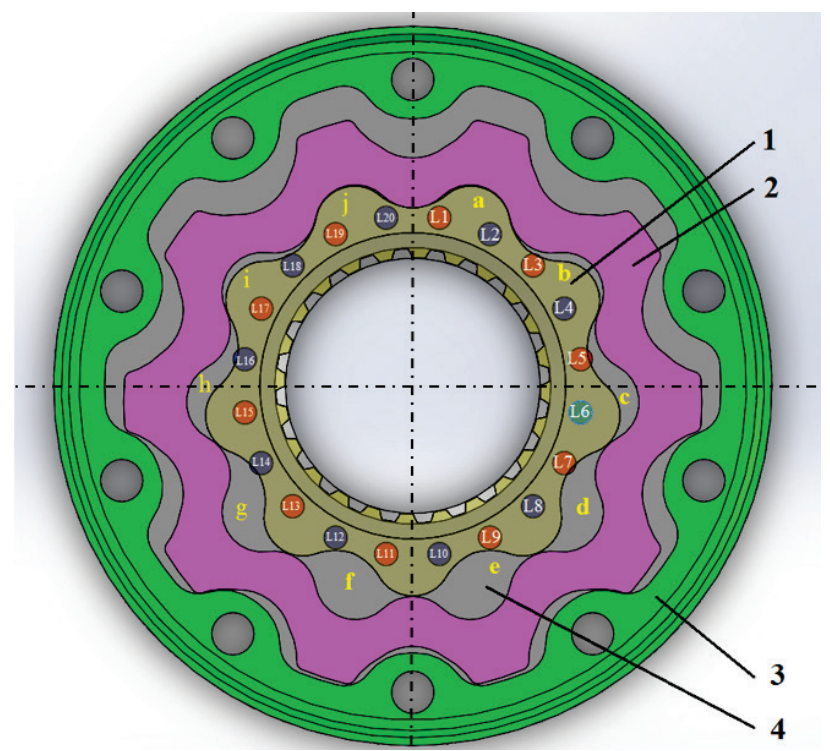

Figure 3 Four basic parts of the hydraulic motor $(\varnothing 174 \mathrm{~mm})$

The inner rotor has 9 teeth and the outer ring has 10 teeth. Together they constitute 10 lobes, which are designated with the small letters in Fig. 3. In the same figure we can recognize twenty holes, which are part of valve plate. The first hole has the mark L1, and the last one L20. Odd numbers represent holes which are connected with the high pressure zone, and even numbers represent holes which are linked to the low pressure zone. As operators, we can change low and high pressure zone with the control valve. The main function of the gerotor housing is the limitation of motion of the outer ring.

\subsection{Gerotor Displacement Volume (ISO 8426)}

Gerotor's displacement volume is very important information that helps us to determine the volumetric and hydraulic-mechanical efficiency of the hydraulic motor. In theory, there are two kinds of displacement volumes. The first one is the theoretic $V_{\mathrm{G}}$ and the second one is the derived displacement volume $V_{\mathrm{I}}$. The difference between them is that the derived displacement volume considers real production tolerances. The estimated deviation between $V_{\mathrm{G}}$ and $V_{\mathrm{I}}$ was 2-3 \% [13].

There exist three methods of determination of derived displacement volume [12]: a) Measurement of displacement volume with the two reservoirs; b) Toetmethod; c) Method regarding ISO 8426. Due to internationally accepted standard, we decided to use the third method. The above mentioned standard ISO 8426 [14] proposes the measurement of volume flow rate with different pressure differences, whereas the speed of shaft of the hydraulic motor is the constant value. We have to determine the volume flow rate for $\Delta p=0$. We can do this graphically with the help of the method of least squares as it is shown in Eq. (1). 


$$
\begin{aligned}
& V_{i}=\left\{\left(\frac{1}{k} \sum_{i=1}^{k} Q_{i}\right)-\right. \\
& \left.-\left[\frac{\frac{1}{k} \sum_{i=1}^{k}\left(\Delta p_{i} Q_{o}\right)-\frac{1}{k^{2}}\left(\sum_{i=1}^{k} \Delta p_{i}\right)\left(\sum_{i=1}^{k} Q_{i}\right)}{\left(\frac{1}{k} \sum_{i=1}^{k} \Delta p_{i}^{2}\right)-\left(\frac{1}{k} \sum_{i=1}^{k} \Delta p_{i}\right)^{2}}\right] \cdot\left(\frac{1}{k} \sum_{i=1}^{k} \Delta p_{i}\right)\right\} \frac{1}{n} .
\end{aligned}
$$

\subsection{Gerotor Efficiency}

The most important fact related to energy consumption of the hydraulic component is efficiency. It represents the ratio between the useful output to the total input, in energy terms. According to hydraulic gerotor motor there are three different types of efficiency:

- total efficiency,

- volumetric efficiency,

- hydraulic-mechanical efficiency.

It is not possible that any of these efficiencies would be greater than $100 \%$ in real applications. In reality, there are many kinds of losses. Volumetric losses include external volumetric losses, internal volumetric losses, losses due to compressibility, losses due to incomplete filing. Hydraulic-mechanical losses represent viscosity friction, friction losses due to turbulent flows, due to pressure differences.

The main purpose of the hydraulic motor is the conversion of hydraulic energy into mechanical energy. Hydraulic energy (Eq. (2)) is a function of volume flow rate and pressure difference, whereas mechanical energy (Eq. (3)) depends on rotational speed and torque.

$E_{h}=Q_{1} \cdot\left(p_{1}-p_{2}\right)$

$E_{m}=2 \pi \cdot n \cdot M$

The total efficiency of the hydraulic motor is the ratio between input hydraulic energy and output mechanical energy as it is shown in Eq. (4).

$\eta_{t}=\frac{2 \pi \cdot n \cdot M}{Q_{1} \cdot\left(p_{1}-p_{2}\right)}$

If we would like to determine volumetric and hydraulic-mechanical efficiency, we have to have information about the derivate displacement volume of hydraulic motor. Volumetric efficiency of the hydraulic motor is a function of rotational speed, derivate displacement volume, and volumetric input flow rate into the hydraulic motor.

$\eta_{v}=\frac{n \cdot V_{i}}{Q_{1}}$

Hydraulic-mechanical efficiency of the hydraulic motor depends on effective torque, pressure difference and derivate displacement volume of the hydraulic motor.

$$
\eta_{h m}=\frac{2 \pi \cdot M}{V_{i} \cdot\left(p_{1}-p_{2}\right)}
$$

\section{METHODOLOGY}

Within the research we investigated the influence of the size of the holes in the valve plate on the hydraulic motor characteristics. According to the previous research activities, we decided to observe hydraulic motor operation in eighteen different measured points which are stated in Tab. 2. We chose two different rotational speeds: $15 \mathrm{~min}^{-1}, \quad 17 \mathrm{~min}^{-1}$ and nine different pressure differences: $16 \mathrm{MPa}, 17 \mathrm{MPa}, 18 \mathrm{MPa}, 19 \mathrm{MPa}, 20 \mathrm{MPa}$, $21 \mathrm{MPa}, 22 \mathrm{MPa}, 23 \mathrm{MPa}, 24 \mathrm{MPa}$. Within the wide set of the measurement activities we took into account recommendations and guidelines from different international standards, whereas we would like to emphasise the importance of the international standard ISO 8426 [14] as well as other standards which are related to different types of hydraulic motor efficiency. Our main purpose was to determine hydraulic motor displacement volume and total, volumetric, and hydraulic-mechanical efficiency of the investigated hydraulic motor.

Table 2 List of eighteen selected measured points

\begin{tabular}{|c|c|c|c|c|c|}
\hline$\#$ & $\begin{array}{c}\text { Rotational } \\
\text { speed } n, \\
\text { min }^{-1}\end{array}$ & $\begin{array}{c}\text { Pressure } \\
\text { difference } \\
\Delta p, \mathrm{MPa}\end{array}$ & $\#$ & $\begin{array}{c}\text { Rotational } \\
\text { speed } n, \\
\text { min }^{-1}\end{array}$ & $\begin{array}{c}\text { Pressure } \\
\text { difference } \Delta p, \\
\mathrm{MPa}\end{array}$ \\
\hline $\mathbf{1}$ & 15 & 16 & $\mathbf{1 0}$ & 17 & 16 \\
\hline $\mathbf{2}$ & 15 & 17 & $\mathbf{1 1}$ & 17 & 17 \\
\hline $\mathbf{3}$ & 15 & 18 & $\mathbf{1 2}$ & 17 & 18 \\
\hline $\mathbf{4}$ & 15 & 19 & $\mathbf{1 3}$ & 17 & 19 \\
\hline $\mathbf{5}$ & 15 & 20 & $\mathbf{1 4}$ & 17 & 20 \\
\hline $\mathbf{6}$ & 15 & 21 & $\mathbf{1 5}$ & 17 & 21 \\
\hline $\mathbf{7}$ & 15 & 22 & $\mathbf{1 6}$ & 17 & 22 \\
\hline $\mathbf{8}$ & 15 & 23 & $\mathbf{1 7}$ & 17 & 23 \\
\hline $\mathbf{9}$ & 15 & 24 & $\mathbf{1 8}$ & 17 & 24 \\
\hline
\end{tabular}

Table 3 Permissible systematic measuring instrument errors [14]

\begin{tabular}{|l|c|c|c|}
\hline \multirow{2}{*}{\multicolumn{1}{|c|}{ Parameter }} & \multicolumn{2}{c|}{$\begin{array}{c}\text { Permissible systematic measuring instrument errprs for } \\
\text { each class of measurement accuracy }\end{array}$} \\
\cline { 2 - 4 } & $\mathrm{A}$ & $\mathrm{B}$ & $\mathrm{C}$ \\
\hline Rotational frequency $(\%)$ & $\pm 0,5$ & \pm 1 & \pm 2 \\
\hline Flow rate (\%) & $\pm 0,5$ & $\pm 1,5$ & $\pm 2,5$ \\
\hline Pressure, $\mathrm{MPa}$ (bar) gauge where $p<0,15(1,5)$ & $\pm 0,001( \pm 0,01)$ & $\pm 0,003( \pm 0,03)$ & $\pm 0,005( \pm 0,05)$ \\
\hline Pressure, $\mathrm{MPa}$ (bar) gauge where $p \geq 0,15(1,5)$ & $\pm 0,05( \pm 0,5)$ & $\pm 0,15( \pm 1,5)$ & $\pm 0,25( \pm 2,5)$ \\
\hline Test fliud temeperature $\left({ }^{\circ} \mathrm{C}\right)$ & $\pm 0,5$ & \pm 1 & \pm 2 \\
\hline
\end{tabular}

All measurements were accomplished in the laboratory for fluid power and controls at the Faculty of Mechanical Engineering, University of Ljubljana. The ambient temperature was $25{ }^{\circ} \mathrm{C}$, whereas the fluid's temperature was $60{ }^{\circ} \mathrm{C}$. One set of the measurements represents 18 measurement points with one specific hole diameter in valve plate - for example, $\varnothing 5,9 \mathrm{~mm}$. For the testing of one set of the measurements we spent around four hours. Two hours for the preparation and measuring installation, and additional two hours for determination of 
physical quantities, which are represented in equations for hydraulic motor efficiency. The uncertainty analysis was done according to the international standard JCGM 100:2008-BIMP [15].

International standard ISO 8426 addresses three classes of measurement accuracy: A, B and C. In Tab. 3 are given permissible systematic measuring instruments errors for each class.

During measurement, we were able to ensure the following errors for desired physical quantities:

- Pressure difference: $\pm 0,05 \mathrm{MPa}$,

- Rotational speed: $\pm 0,1 \mathrm{~min}^{-1}$,

- Fluid Temperature: $\pm 1{ }^{\circ} \mathrm{C}$.

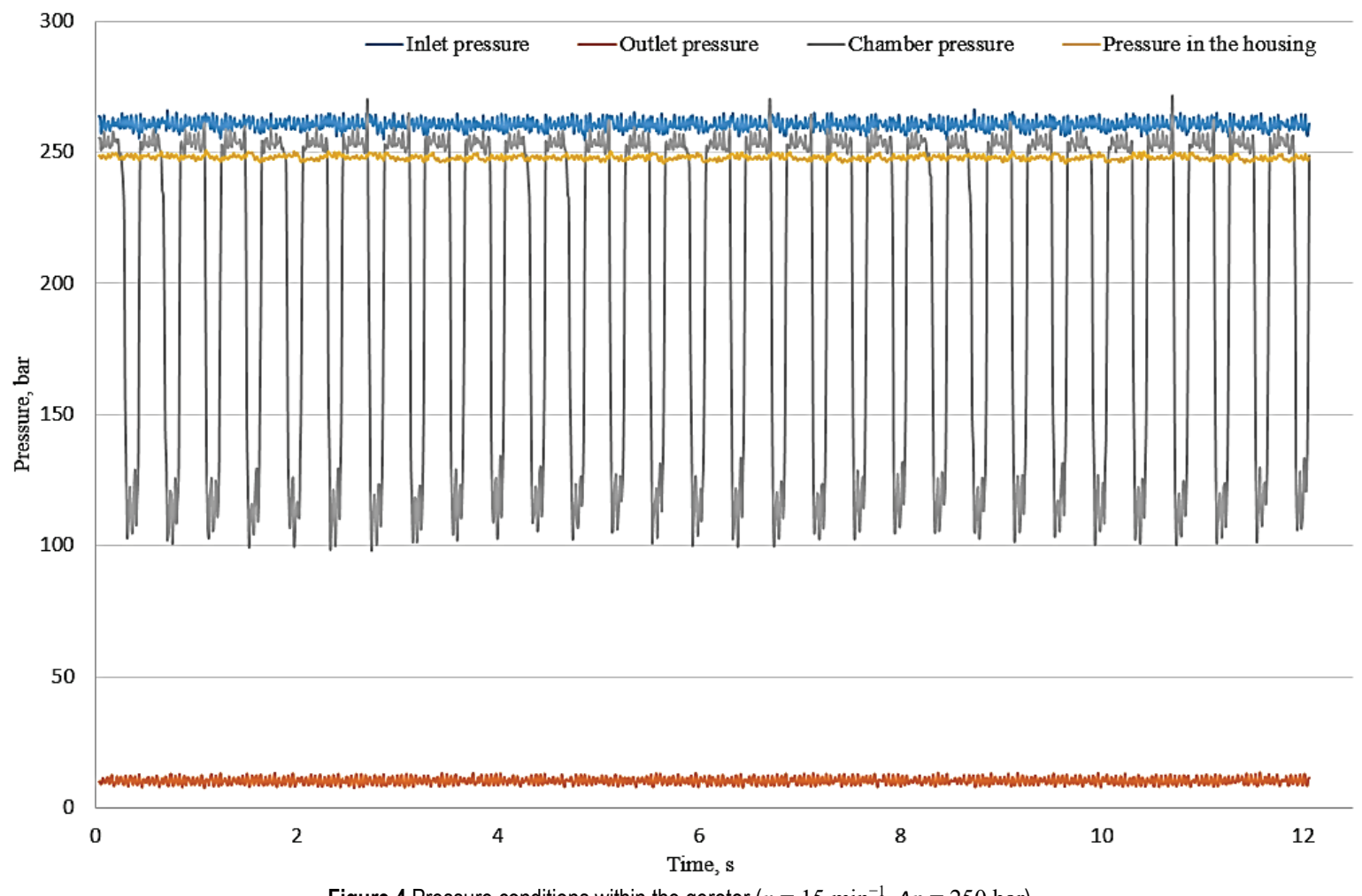

The original diameter of holes in the valve plate was $\varnothing 5,5 \mathrm{~mm}$ (Fig. 5). It was the first set of the measurements. Every additional set had $0,2 \mathrm{~mm}$ incremental increase in hole diameter. The maximal hole diameter was $\varnothing 7,1 \mathrm{~mm}$ (Fig. 6).

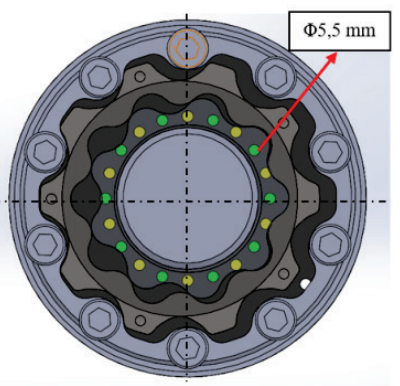

Figure 5 The minimal hole size $(\varnothing 5,5 \mathrm{~mm})$ in the valve plate $(\varnothing 174$ $\times 15 \mathrm{~mm}$ )

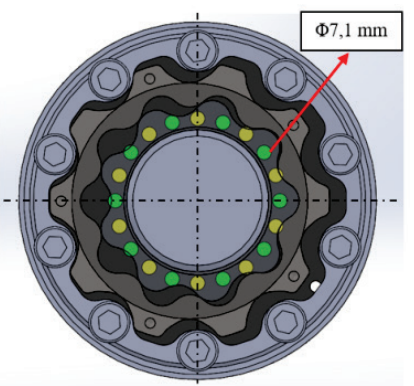

Figure 6 The maximal hole size $(\varnothing 7,1 \mathrm{~mm})$ in the valve plate $(\varnothing 174 \times 15 \mathrm{~mm})$
To summarize, hole diameter in the valve plate was the only parameter which was being changed. As an objective function we selected the total efficiency of hydraulic gerotor motor.

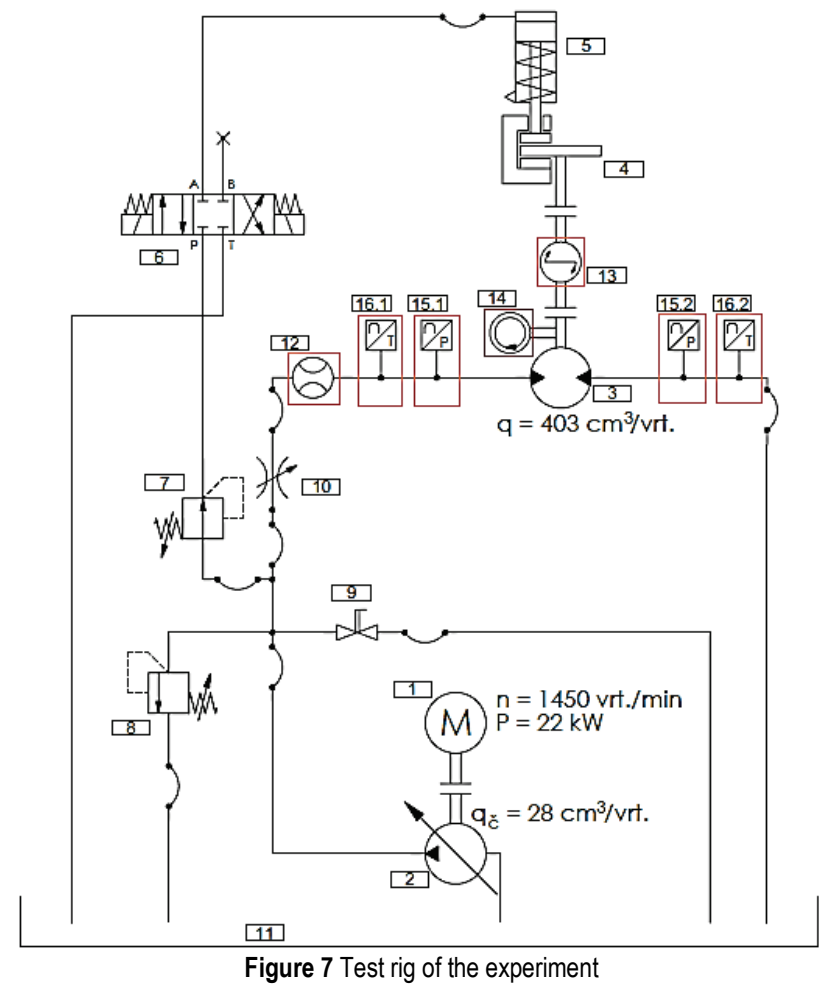




\section{TEST RIG}

Referring to Fig. 7, the test rig of the experiment consisted of sixteen different hydraulic components, whereas we would like to describe just the most important parts. The experiment was carried out by (1) - the electromotor and (2) - variable displacement pump. The tested hydraulic motor is denoted with the number (3). We used (7) - pressure reduction valve and (8)-pressure relief valve. Five different physical quantities have been measured.
We applied (12) - volume flow rate meter, (13) torque sensor, (14) - rotational speed sensor, (15) pressure sensor and (16) - temperature sensor.

If we would like to determine different kind of efficiencies of the hydraulic motor, we have to measure the physical units properly in the sense of location of sensors. We would like to emphasize that on the inlet flow side we have to measure flow rate $\left(Q_{1}\right)$ and pressure $\left(p_{1}\right)$. On the other hand, outlet pressure $\left(p_{2}\right)$ is absolutely essential, because the pressure difference of the inlet and outlet flow of the hydraulic motor is very important.

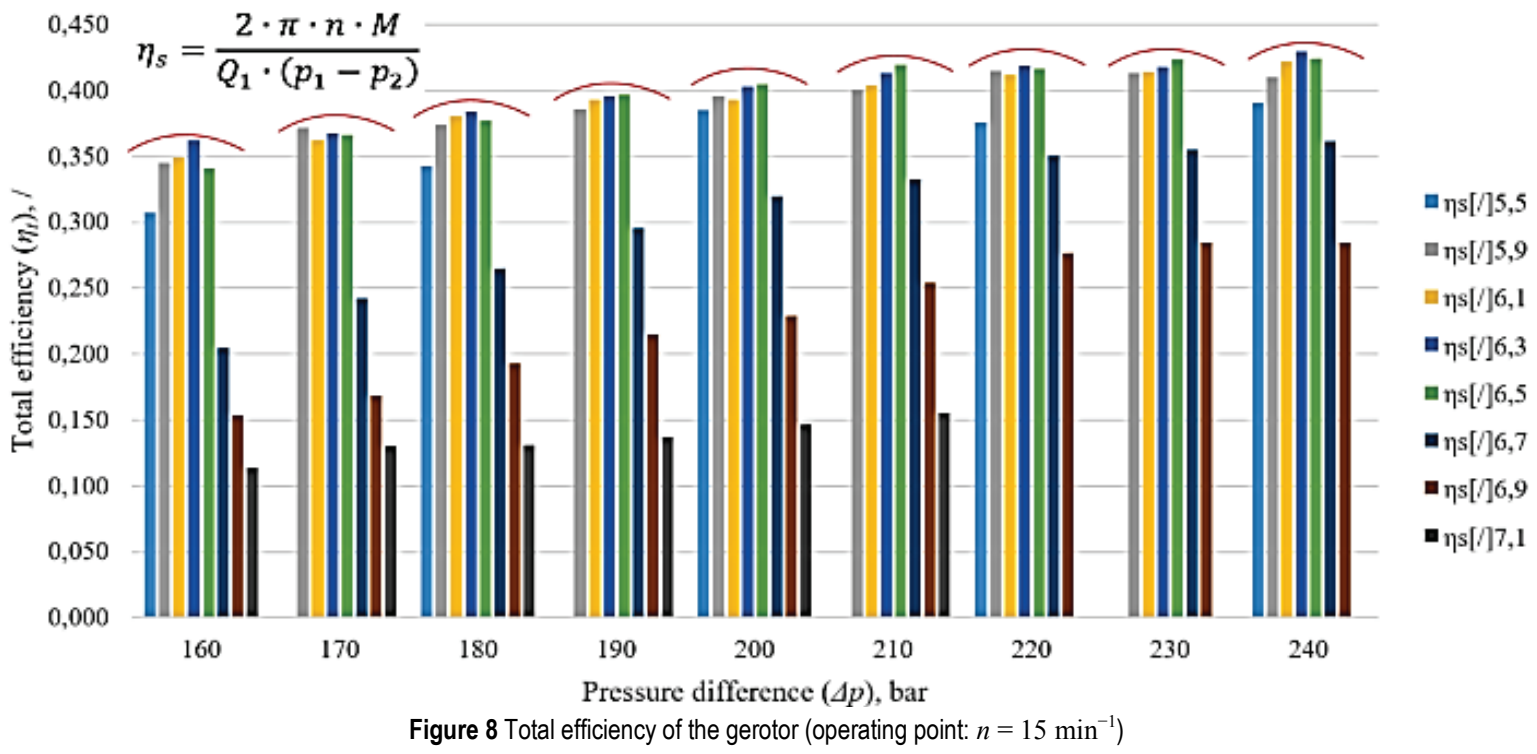

\section{RESULTS AND DISCUSSION}

\subsection{Pressure Conditions within the Gerotor}

Although the hydraulic gerotor motor has few mechanical components, its principle of operation is quite complicated. In the very beginning of the results presentation, we would like to introduce pressure conditions within the gerotor. In figure 8 are presented the results of pressure measurements within the gerotor. We observed four different pressures:

- Inlet pressure: pressure at the inlet port of gerotor,

- Outlet pressure: pressure at the outlet port of gerotor,

- Chamber pressure: pressure in the space between the inner rotor and the outer ring,

- Pressure in the housing: pressure in the space between the outer ring and the gerotor housing.

\subsection{Influence of the Size of the Holes in the Valve Plate on Efficiency}

The most important results of the research activities are presented in Fig. 8 and Fig. 9, which show the relationship between total efficiency and size of the holes in the valve plate. Different colours represent different holes' size. There is pressure difference (range: from 160 bar to 240 bar) on the $x$-axis and total efficiency (range: $0-45 \%$ ) on the $y$-axis.

The height of a column represents a specific value of the total efficiency in a specific measured point. The greater the height of the column, the greater the total efficiency of the hydraulic gerotor motor.
If we take a look at Fig. 8 and put a focus on the first set (first 8 columns) of the results, we see that the initial total efficiency of gerotor with the valve plate with the diameter $\varnothing 5,5 \mathrm{~mm}$ was $30,7 \%$ (first column of the set). The highest total efficiency was $36,2 \%$, returning an 18 $\%$ higher total efficiency compared to the initial state.

The highest total efficiency was obtained with the hole diameter of $\varnothing 6,3 \mathrm{~mm}$. The additional increase of the hole diameter had a negative influence on the gerotor characteristics - total efficiency dropped down dramatically. For example, the total efficiency of the gerotor with the valve plate with hole diameter $\varnothing 7,1 \mathrm{~mm}$ was just $11,4 \%$. There exists almost the same trend for every set of pressure differences. In general, we found out that the total efficiency increases with the increase of pressure differences if we observe the total efficiency of one specific hole diameter. For example, the total efficiency values for hole diameter of $\varnothing 6,7 \mathrm{~mm}$ were increasing in the following way: 20,5\%, 24,3\%, 26,5\%, $29,5 \%, 32,0 \%, 33,3 \%, 35,1 \%, 35,5 \%, 36,2 \%$.

When we accomplished the measurement of the gerotor with rotational speed $17 \mathrm{~min}^{-1}$, we found out that there exist similarities with the results of gerotor with rotational speed $15 \mathrm{~min}^{-1}$. In the very beginning we expected similar trends in both cases. If we look at the results in the second case, we can find out that gerotor has a slightly lower total efficiency. A red arc above each column represents total efficiency trend for each set of the results. There exists the increasing and the decreasing trend of total efficiency within every set of measurements. 
If we focus on the total efficiency in both cases $\left(n=15 \mathrm{~min}^{-1}, n=17 \mathrm{~min}^{-1}\right)$, we can see that the total efficiency was higher in case of slightly larger holes. In the initial state, total efficiency was relatively low. When we enlarged hole diameter from $\varnothing 5,5 \mathrm{~mm}$ to $\varnothing 6,3 \mathrm{~mm}$, the hydraulic motor reached the maximum total efficiency in a few sets of meausurements. Additional escalation of the hole diameter led to lower total efficiency. In some cases, the holes are so big that the hydraulic motor couldn't operate.

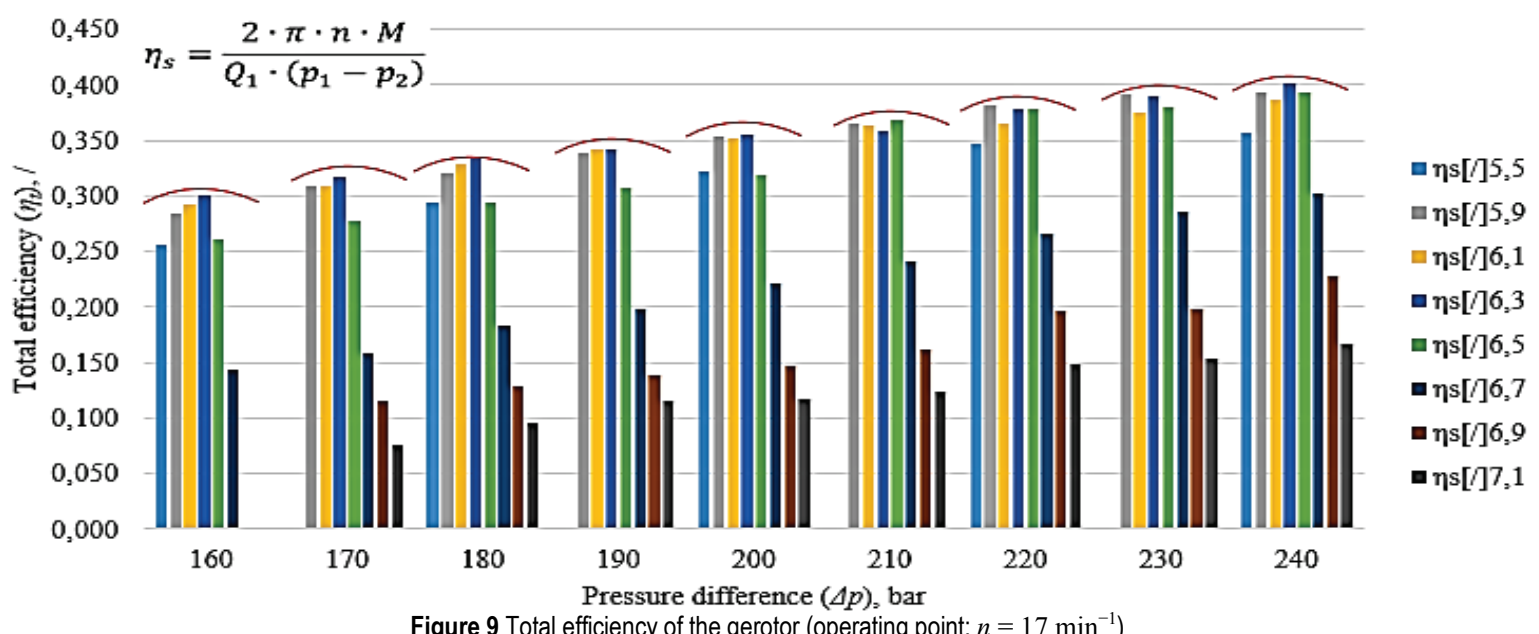

To conclude, we found out that a hole diameter of $\varnothing 6,3 \mathrm{~mm}$ is the most appropriate size of holes in the valve plate regarding total efficiency of the hydraulic gerotor motor. In this case, the total efficiency is around $5 \%$ higher on average.

\subsection{Uncertainty Analysis}

Within the research activities we measured 5 physical quantities: pressure, flow rate, torque, rotational speed, and temperature. Briefly, we would like to present the uncertainty analysis for the first four physical units. The expanded uncertainty analysis was done by assuming triangular and rectangular distribution and a coverage factor $=2$ (Tab. 4).

\begin{tabular}{|l|c|c|}
\hline \multicolumn{1}{|c|}{ Table 4 Expanded uncertainty analysis } \\
\begin{tabular}{|l|c|c|}
\hline & $\begin{array}{c}\text { Rectangular } \\
\text { distribution (\%) }\end{array}$ & $\begin{array}{c}\text { Triangular } \\
\text { distribution }(\%)\end{array}$ \\
\hline Pressure & 1,50 & 1,06 \\
\hline Flow rate & 1,73 & 1,22 \\
\hline Torque & 2,02 & 1,43 \\
\hline Rotational speed & 1,73 & 1,22 \\
\hline
\end{tabular}
\end{tabular}

\section{CONCLUSION}

A hydraulic gerotor motor with the floating outer ring was discussed in this paper. The pressure and efficiency characteristics of the above mentioned special type of hydraulic motor are presented. Pressure conditions are introduced through four distinctive pressures: inlet, outlet, chamber pressure and pressure in the housing. The dynamic of chamber pressure was determined. The conclusion of this study can be summarized as follows:

- Within the pressure measurement in the gerotor chambers we found out that there is almost constant pressure in the housing.

- Due to continuous operation of hydraulic gerotor motor and symetry of gerotor's parts, a pattern of alternating chamber pressure was recognized.
- The diameter of the holes in the valve plate influences the total efficiency of the hydraulic gerotor motor.

- For each set of the measurements exists an optimal diameter of holes.

- Very high total efficiencies were reached with the holes' diameter being $\varnothing 6,3 \mathrm{~mm}$ in most cases.

- The highest total efficiency was on average $5 \%$ higher than the total efficiency of the original hole size. It means that a hydraulic motor with the hole diameter $\varnothing 6,3 \mathrm{~mm}$ in the valve plate has on average $5 \%$ better operation characteristics in every measured point than a hydraulic motor with the hole size $\varnothing 5,5 \mathrm{~mm}$ in the valve plate.

We can conclude that we would be able to optimize the gerotor's operation with some simple mechanical operation. With drilling we can make hole diameter larger to raise the total efficiency of the gerotor by around $5 \%$ on average. This happens if the diameter of holes in the valve plate is $\varnothing 6,3 \mathrm{~mm}$.
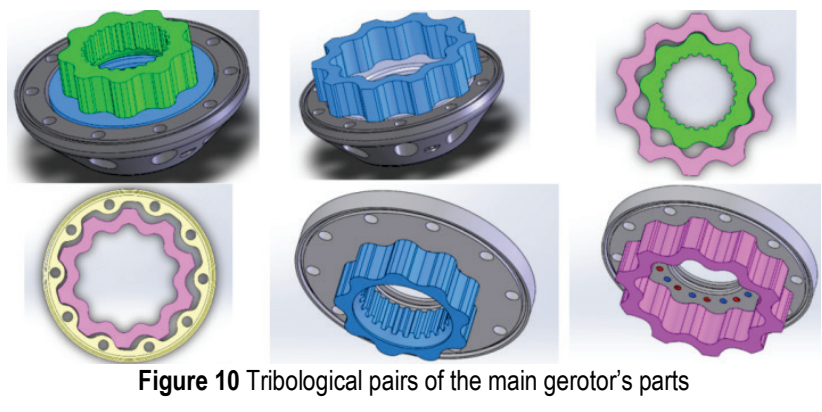

The results and research findings present a very important contribution to science. Hydraulic gerotor motors with the floating outer ring were very rarely discussed in scientific papers. There is a lack of such analysis in literature. Pressure determination and influence of hole diameter in the valve plate on total efficiency of hydraulic gerotor motors represents novelty 
and original insight in the gerotor's group of hydraulic motors.

In future research activities we will focus on the tribological pairs of the main gerotor's parts (Fig.10). We would like to investigate tribological conditions, and estimate how they influence the total efficiency of the hydraulic gerotor motor.

\section{Acknowledgements}

The authors greatly acknowledge the Slovenian Research Agency (ARRS) and the company KGL d.o.o. Slovenia.

\section{Nomenclature}

\begin{tabular}{|c|c|l|}
\hline Symbol & SI Units & \multicolumn{1}{|c|}{ Explanation } \\
\hline$i$ & & Index \\
\hline$k$ & & Number of samples \\
\hline$n$ & $\mathrm{~min}^{-1}$ & Rotational speed \\
\hline$p_{1}$ & bar & Pressure at the inlet port of hydraulic motor \\
\hline$p_{2}$ & bar & Pressure at the outlet port of hydraulic motor \\
\hline$E_{h}$ & & Hydraulic energy \\
\hline$E_{m}$ & & Mechanical energy \\
\hline$M$ & $\mathrm{Nm}$ & Torque \\
\hline$Q_{1}$ & $\mathrm{~m}^{3} \cdot \mathrm{s}^{-1}$ & $\begin{array}{l}\text { Volume flow rate at the inlet port of hydraulic } \\
\text { motor }\end{array}$ \\
\hline$V_{g}$ & $\mathrm{~m}^{3}$ & Geometric displacement volume \\
\hline$V_{i}$ & $\mathrm{~m}^{3}$ & Derived displacement volume \\
\hline$\eta_{h m}$ & & Hydraulic-mechanical efficiency \\
\hline$\eta_{v}$ & & Volumetric-efficiency \\
\hline$\eta_{t}$ & & Total efficiency \\
\hline
\end{tabular}

\section{REFERENCES}

[1] Michael, P., Burgess, K., Kimball, A., \& Wanke, T. (2009). Hydraulic Fluid Efficiency Studies in Low-Speed HighTorque Motors. SAE Technical Paper 2009-01-2848.7. https://doi.org/10.4271/2009-01-2848

[2] Bae, J. H., Lee, H. R., \& Kim, C. (2015). Optimal Design of Gerotor with Combined Profiles (Three-Ellipse and Ellipse- Involute-Ellipse) Using Rotation and Translation Algorithm. Transactions of the Korean Society of Mechanical Engineers A, 39(2), 169-177. https://doi.org/10.3795/KSME-A.2015.39.2.169

[3] Sang, X., Zhou, X., \& Liu, X. (2015). Performance optimization of an oil ellipse gerotor pump for automotive engine. 5th International Conference on Advanced Design and Manufacturing Engineering (ICADME) / Indonesia, 1686-1690. https://doi.org/10.2991/icadme-15.2015.312

[4] Jacazio, G. \& De Martin, A. (2016). Influence of rotor profile geometry on the performance of an original lowpressure gerotor pump. Mechanism and Machine Theory, 100, 296-312. https://doi.org/10.1016/j.mechmachtheory.2016.02.012

[5] Dong, X. (2002). Multi-Objective Optimization Design of Gerotor Orbit Motors. SAE Technical Paper 2002-01-1350. https://doi.org/10.4271/2002-01-1350

[6] Ding, H., Lu, X. J., \& Jiang, B. (2012). A CFD model for orbital gerotor motor. IOP Conference Series: Earth and Environmental Science, 15(6). https://doi.org/10.1088/1755-1315/15/6/062006

[7] Mishev, A. \& Stehle, T. (2015). CFD-Analyse zur Leistungssteigerung eines Orbit-Motors, Untersuchung des Einflusses von Rotorzähnezahl und Exzentrizität auf die Performance des Motors.

[8] Conrad, F., Trostmann, E., \& Zhang, M. (1993). Experimental identification and modelling of flow and torque losses in gerotor hydraulic motors. Proceedings of the JFPS International Symposium on Fluid Power, 2, 677682. https://doi.org/10.5739/isfp.1993.677

[9] Garcia, J. M. (2011). Surface effects on start-up friction and their application to compact gerotor motor design. http://search.proquest.com/docview/900865878?accountid= $16468(29.11 .2016)$

[10] Furustig, J., Almqvist, A., Pelcastre, L., Bates, C. A., Ennemark, P., \& Larsson, R. (2015) A strategy for wear analysis using numerical and experimental tools, applied to orbital type hydraulic motors. http://pic.sagepub.com/ content/early/2015/06ogled/10/0954406215590168 (29.11.2016)

[11] Ranganathan, G., Hillson Samuel Raj, T., \& Mohan Ram, P.V. (2004). Wear characterisation of small PM rotors and oil pump bearings. Tribology International, 37(1), 1-9. https://doi.org/10.1016/S0301-679X(03)00109-9

[12] Ivantysyn, J. \& Ivantysynova, M. (2000). Hydrostatic Pumps and Motors. First English Edition, Akademia Books International.

[13] Schlösser, W. M. J. \& Hildbrands, J. W. (1963). Das theoretische Hubvolumen von Verdrängermaschinen. Ölhydraulik und Pneumatik, 7(4).

[14] Standard ISO 8426:2008, Hydraulic fluid power, Positive displacement pumps and motors, Determination of derived capacity

[15] Evaluation of measurement data - Guide to the expression of uncertainty in measurement, JCGM 100:2008, GUM 1995 with minor correction, 2008.

[16] Toet, G. (1970). Die Bestimmung des theoretischen Hubvolumens von hydrostatischen Verdrängerpumpen und -motoren aus volumetrischen Messungen. Ölhydraulik und pneumatik, 14(5).

\section{Contact information:}

Ervin STRMČNIK, PhD student, Corresponding Author University of Ljubljana, Faculty of Mechanical Engineering Aškerčeva 6, 1000 Ljubljana, Slovenia

ervin.strmcnik@fs.uni-lj.si

Franc MAJDIČ, Assist. Prof. Dr.

University of Ljubljana, Faculty of Mechanical Engineering Aškerčeva 6, 1000 Ljubljana, Slovenia

franc.majdic@fs.uni-lj.si 